\title{
Clinical significance of conformity index and gradient index in patients undergoing stereotactic radiosurgery for a single metastatic tumor
}

\author{
Hitoshi Aiyama, MD, ${ }^{1,2}$ Masaaki Yamamoto, MD, PhD, ${ }^{1,4}$ Takuya Kawabe, MD, PhD, ${ }^{5}$ \\ Shinya Watanabe, MD, PhD, ${ }^{3}$ Takao Koiso, MD, PhD, ${ }^{2}$ Yasunori Sato, PhD, ${ }^{6}$ \\ Yoshinori Higuchi, MD, PhD, ${ }^{7}$ Eiichi Ishikawa, MD, PhD, ${ }^{2}$ Tetsuya Yamamoto, MD, PhD, ${ }^{8}$ \\ Akira Matsumura, MD, PhD, ${ }^{2}$ and Hidetoshi Kasuya, MD, $\mathrm{PhD}^{4}$
}

\begin{abstract}
${ }^{1}$ Katsuta Hospital Mito GammaHouse, Hitachi-naka; ${ }^{2}$ Department of Neurosurgery, Faculty of Medicine, and ${ }^{3} T$ sukuba Clinical Research and Development Organization, University of Tsukuba, Tsukuba; ‘Department of Neurosurgery, Tokyo Women's Medical University, Medical Center East, Tokyo; ${ }^{5}$ Department of Neurosurgery, Rakusai Shimizu Hospital, Kyoto; ${ }^{6}$ Department of Preventive Medicine and Public Health, Keio University School of Medicine, Tokyo; ${ }^{7}$ Department of Neurological Surgery, Chiba University Graduate School of Medicine, Chiba; and ${ }^{8}$ Department of Neurosurgery, Graduate School of Medicine, Yokohama City University, Yokohama, Japan
\end{abstract}

OBJECTIVE Although the conformity index ( $\mathrm{Cl}$ ) and the gradient index ( $\mathrm{Gl})$, which were proposed by Paddick and colleagues, are both logically considered to correlate with good posttreatment results after stereotactic radiosurgery (SRS), this hypothesis has not been confirmed clinically. The authors' aim was to reappraise whether high $\mathrm{Cl}$ values correlate with reduced tumor progression rates, and whether low $\mathrm{Gl}$ values correlate with reduced complication incidences.

METHODS This was an institutional review board-approved, retrospective cohort study conducted using a prospectively accumulated database including 3271 patients who underwent Gamma Knife SRS for brain metastases (BMs) during the 1998-2016 period. Among the 3271 patients, 925 with a single BM at the time of SRS (335 women and 590 men, mean age 66 [range 24-93] years) were studied. The mean/median Cls were $0.62 / 0.66$ (interquartile range [IQR] 0.53-0.74, range 0.08-0.88) and the mean/median Gls were 3.20/3.09 (IQR 2.83-3.39, range 2.27-11.4).

RESULTS SRS-related complications occurred in 38 patients (4.1\%), with a median post-SRS interval of 11.5 (IQR 6.0-25.8, maximum 118.0) months. Cumulative incidences of post-SRS complications determined by a competing risk analysis were $2.2 \%, 3.2 \%, 3.6 \%, 3.8 \%$, and $3.9 \%$ at the 12 th, 24th, 36th, 48th, and 60th post-SRS month, respectively. Multivariable analyses showed that only two clinical factors (i.e., peripheral doses and brain volume receiving $\geq 12$ Gy) correlated with complication rates. However, neither Cls nor Gls impacted the incidences of complications. Among the 925 patients, post-SRS MRI was performed at least once in 716 of them, who were thus eligible for local progression evaluation. Among these 716 patients, local progression was confirmed in 96 (13.4\%), with a median post-SRS interval of 10.8 (IQR 6.7-19.5, maximum 59.8) months. Cumulative incidences of local progression determined by a competing risk analysis were $7.7 \%, 12.6 \%, 14.2 \%, 14.8 \%$, and $15.3 \%$ at the 12 th, 24th, 36th, 48th, and 60th post-SRS month, respectively. Multivariable analyses showed neurological symptoms, extracerebral metastases, repeat SRS, and Cls to correlate with incidences of local progression, whereas GIs had no impact on local tumor progression. Particularly, cumulative incidences of local progression were significantly lower in patients with $\mathrm{Cls}<0.65$ than in those with $\mathrm{Cls} \geq 0.65$ (adjusted hazard ratio 1.870,95\% confidence interval 1.299-2.843; $p=0.0034$ ).

CONCLUSIONS To the authors' knowledge, this is the first analysis to focus on the clinical significance of $\mathrm{Cl}$ and $\mathrm{Gl}$ based on a large series of patients with BM. Contrary to the majority opinion that dose planning with higher $\mathrm{Cl}$ and lower

ABBREVIATIONS BM = brain metastasis; $\mathrm{Cl}$ = conformity index; $\mathrm{GI}$ = gradient index; $\mathrm{GK}=$ Gamma Knife; HR = hazard ratio; IQR = interquartile range; KPS = Karnofsky Performance Scale; NSCLC = non-small cell lung cancer; RTOG = Radiation Therapy Oncology Group; SRS = stereotactic radiosurgery; WBRT = whole-brain radiotherapy. SUBMITTED May 12, 2018. ACCEPTED June 12, 2018.

INCLUDE WHEN CITING DOI: 10.3171/2018.6.GKS181314. 
GI results in good post-SRS outcomes (i.e., low local progression rates and minimal complications), this study clearly showed that the lower the Cls were, the lower the local progression rates were, and that the GI did not impact complication rates.

https://thejns.org/doi/abs/10.3171/2018.6.GKS181314

KEYWORDS brain metastases; radiosurgery; Gamma Knife; conformity index; gradient index; stereotactic radiosurgery; oncology

$\mathrm{F}$ OR dose planning in stereotactic radiosurgery (SRS), the conformity index $(\mathrm{CI}$; the coverage ratio multiplied by the selectivity ratio) and the gradient index (GI; the brain volume receiving 50\% of the planned peripheral dose divided by the target volume), which were proposed by Paddick and colleagues, ${ }^{10,11}$ are generally believed to be essential for obtaining good treatment results. Namely, either higher CIs (i.e., closer to 1.0) or lower GIs are expected to achieve good tumor growth control and to reduce irradiation-related complications. Although this hypothesis is generally accepted as being logically correct, surprisingly little information is available regarding its clinical significance. Our aim is to reappraise whether the above-mentioned hypothesis is actually clinically valid in patients with a single brain metastasis (BM) undergoing SRS.

\section{Methods \\ Patient Population}

This retrospective study was approved by the institutional review board of the Tokyo Women's Medical University, Tokyo. Our prospectively accumulated data set consisted of 3271 consecutive patients with BM treated with Gamma Knife (GK) SRS at the Mito GammaHouse during the 18-year period between July 1998 and June 2016. Among the 3271 patients, excluding 4 who were lost to follow-up, 925 with a single BM at the time of treatment (335 women and 590 men, mean age 66 [range 24-93] years) who underwent SRS were studied (Fig. 1). Pre-SRS clinical characteristics are summarized in Table 1. Prior to referral to us for SRS, treatment selections had generally been made by the patients' primary physicians, such that different patient selection criteria had been applied. Therefore, the second author (M.Y.) judged whether or not SRS was indicated for each patient. The treatment strategies were explained in detail to each patient, as well as to

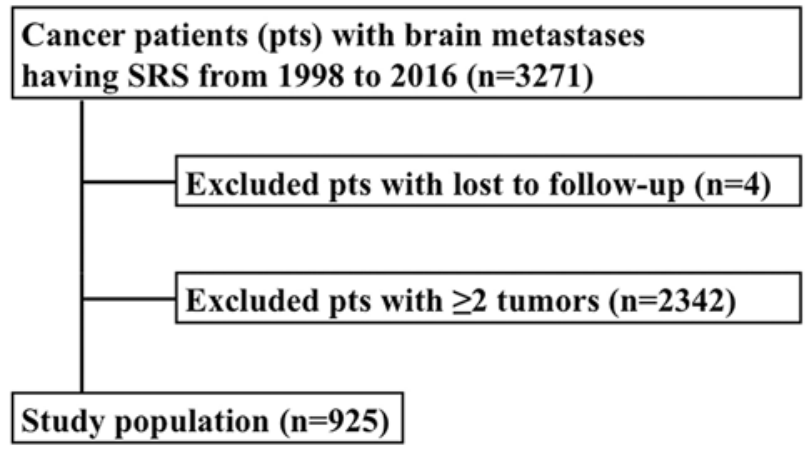

FIG. 1. Flow diagram outlining patient selection for this study. at least one adult relative, and written informed consent was obtained from all patients by the second author before SRS procedures were performed. Prior to SRS, surgical removal had been performed in 189 patients $(20.4 \%)$ and whole-brain radiotherapy (WBRT) had been done in 27 (2.9\%).

\section{Radiosurgical Techniques}

A stereotactic coordinate frame (Leksell Model G frame; Elekta Instruments AB) was applied under local anesthesia, supplemented with mild sedation in some cases. For target coordinate determination and dose planning, stereotactic Gd-enhanced T1-weighted axial MR images with a slice thickness of $2 \mathrm{~mm}$, multiple slices of which covered the entire brain, were obtained. For dose planning, the Leksell GammaPlan (Elekta) was used. GK SRS was performed using a Leksell GK Model B unit (Elekta) from July of 1991 through June of 2003, a Leksell GK Model C unit (Elekta) from July of 2003 through November of 2013, and thereafter, a Leksell GK Perfexion (Elekta) through June of 2016. Standard, single-session GK SRS was performed. However, in 35 patients (3.8\%) in whom the tumor volume was large, a 3-stage treatment was applied. ${ }^{3}$ Our dose selection was based on our experiences accumulated during the 7-year period between 1992 and 1998 in Japan. The median dose at the tumor periphery was 22.00 (interquartile range [IQR] 20.00-24.00, maximum 25.00) Gy. In this series, peripheral doses of $15.00-25.00$ Gy were used in more than $99 \%$ of patients. Radiosurgical parameters are summarized in Table 2. The mean/median CIs were 0.62/0.66 (IQR 0.53-0.74, range $0.08-0.88$ ) and the mean/median GIs were 3.20/3.09 (IQR 2.83-3.39, range 2.27-11.4).

\section{Clinical Outcomes}

Local progression and SRS-related symptomatic complications were analyzed in relation to the CIs and the GIs. Patients were recommended to undergo post-SRS MRI follow-up at a 2- to 3-month interval. Criteria for local progression (i.e., progression of the SRS-irradiated lesion) were usually an increase in the size of the enhanced area on post-Gd T1-weighted MR images and an enlarged tumor core on T2-weighted MR images as well as detection of a high choline peak on proton MR spectrograms. ${ }^{5}$ However, in some cases in which MRI raised suspicion of progression, methionine PET was also used to confirm whether or not the tumor had progressed.,

Regarding SRS-related symptomatic complications, treatment was considered to have failed in those with worse than Radiation Therapy Oncology Group (RTOG) grade 2 neurotoxicity. ${ }^{12}$ However, treatments in 4 patients with RTOG grade 0 and 1 patient with grade 1 were clas- 
TABLE 1. Summary of preradiosurgical demographic characteristics

\begin{tabular}{|c|c|}
\hline Characteristic & Value \\
\hline No. of patients & 925 \\
\hline \multicolumn{2}{|l|}{ Age (yrs) } \\
\hline Median & 67 \\
\hline Range & $24-93$ \\
\hline IQR & $59-74$ \\
\hline \multicolumn{2}{|l|}{ Sex } \\
\hline Male & $590(63.8)$ \\
\hline Female & $335(36.2)$ \\
\hline \multicolumn{2}{|l|}{ Neurological symptoms } \\
\hline Yes & $490(53.0)$ \\
\hline No & $435(47.0)$ \\
\hline \multicolumn{2}{|l|}{ KPS score } \\
\hline$\geq 80 \%$ & $736(79.6)$ \\
\hline$<70 \%$ & $189(20.4)$ \\
\hline \multicolumn{2}{|l|}{ Modified RPA class ${ }^{*}$} \\
\hline $1+2 a$ & $446(48.2)$ \\
\hline $2 b$ & $295(31.9)$ \\
\hline $2 c+3$ & $184(19.9)$ \\
\hline \multicolumn{2}{|l|}{ Primary cancer } \\
\hline NSCLC & $497(53.7)$ \\
\hline SCLC & $61(6.6)$ \\
\hline Breast & $78(8.4)$ \\
\hline Gastrointestinal tract & $147(15.9)$ \\
\hline Kidney & $51(5.5)$ \\
\hline Others & $91(9.8)$ \\
\hline \multicolumn{2}{|l|}{ Presentation } \\
\hline Synchronous & $140(15.1)$ \\
\hline Metachronous & $785(84.9)$ \\
\hline \multicolumn{2}{|l|}{ Primary cancer status } \\
\hline Controlled & $372(40.2)$ \\
\hline Uncontrolled & $553(59.8)$ \\
\hline \multicolumn{2}{|l|}{ Extracranial metastases } \\
\hline Yes & $415(44.9)$ \\
\hline No & $510(55.1)$ \\
\hline \multicolumn{2}{|l|}{ Prior surgery } \\
\hline Yes & $189(20.4)$ \\
\hline No & $736(79.6)$ \\
\hline \multicolumn{2}{|l|}{ Prior WBRT } \\
\hline Yes & $27(2.9)$ \\
\hline No & 898 (97.1) \\
\hline
\end{tabular}

RPA = recursive partitioning analysis; $S C L C=$ small cell lung cancer. Values are presented as the number of patients (\%) unless otherwise indicated.

${ }^{*}$ Categorized according to Yamamoto and colleagues. ${ }^{21,23}$

sified as failures because either steroid administration or surgical intervention was required to prevent possible neurological deterioration during further observation.

All of these criteria for local progression and complications have remained consistent for more than 20 years at
TABLE 2. Summary of radiosurgical parameters

\begin{tabular}{|c|c|}
\hline Characteristic & Value \\
\hline \multicolumn{2}{|l|}{ Tumor vol $\left(\mathrm{cm}^{3}\right)$} \\
\hline Median & 4.6 \\
\hline Range & $0.01-126.2$ \\
\hline IQR & $1.21-9.62$ \\
\hline \multicolumn{2}{|c|}{ Min absorbed dose to the tumor (Gy) } \\
\hline Median & 22.00 \\
\hline Range & $5.80-25.00$ \\
\hline IQR & $20.00-24.00$ \\
\hline \multicolumn{2}{|c|}{ Max absorbed dose to the tumor (Gy) } \\
\hline Median & 36.00 \\
\hline Range & $20.00-60.00$ \\
\hline IQR & $30.00-40.00$ \\
\hline \multicolumn{2}{|c|}{ Total absorbed energy to the whole skull (Joules) } \\
\hline Median & 2.7 \\
\hline Range & $0.2-11.7$ \\
\hline IQR & $1.25-3.9$ \\
\hline \multicolumn{2}{|c|}{ Mean absorbed dose to the whole skull (Gy) } \\
\hline Median & 0.7 \\
\hline Range & $0.1-3.2$ \\
\hline IQR & $0.3-1.1$ \\
\hline \multicolumn{2}{|c|}{ Whole skull vol receiving $\geq 5$ Gy $\left(\mathrm{cm}^{3}\right)$} \\
\hline Median & 69.0 \\
\hline Range & $0.7-857.6$ \\
\hline IQR & $19.3-119.3$ \\
\hline \multicolumn{2}{|c|}{ Whole skull vol receiving $\geq 12$ Gy $\left(\mathrm{cm}^{3}\right)$} \\
\hline Median & 18.5 \\
\hline Range & $0.1-169.4$ \\
\hline IQR & $5.1-32.7$ \\
\hline \multicolumn{2}{|l|}{$\mathrm{Cl}$} \\
\hline Median & 0.66 \\
\hline Range & $0.08-0.88$ \\
\hline IQR & $0.53-0.74$ \\
\hline \multicolumn{2}{|l|}{$\mathrm{Gl}$} \\
\hline Median & 3.09 \\
\hline Range & $2.27-11.4$ \\
\hline IQR & $2.83-3.39$ \\
\hline
\end{tabular}

Max $=$ maximum; $\min =$ minimum .

our facilities and have also been widely confirmed based on our previous publications. . $^{6,16,18-20,22,24}$

\section{Statistical Analysis}

All data were analyzed according to the intention-totreat principle. For baseline variables, summary statistics were constructed that used frequencies and proportions for categorical data and means or median and IQR for continuous variables. For the time-to-event outcome analyses of the aforementioned end point, a competing risk analysis was applied because death is a competing risk for this end point. ${ }^{1,2}$

We performed univariable analyses of the CIs and GIs 
TABLE 3. Cumulative incidences of complications after SRS

\begin{tabular}{|c|c|c|c|c|c|c|c|c|c|}
\hline \multirow{2}{*}{$\begin{array}{l}\text { Cumulative } \\
\text { Incidences }\end{array}$} & \multirow[b]{2}{*}{ No. } & \multicolumn{5}{|c|}{ Mos After SRS } & \multirow{2}{*}{$\begin{array}{c}\text { Adjusted } \\
\text { HR }\end{array}$} & \multirow{2}{*}{$\begin{array}{l}95 \% \text { Confidence } \\
\text { Interval }\end{array}$} & \multirow{2}{*}{$\begin{array}{c}p \\
\text { Value }\end{array}$} \\
\hline & & 12 & 24 & 36 & 48 & 60 & & & \\
\hline Overall & 925 & 0.022 & 0.032 & 0.036 & 0.038 & 0.039 & & & \\
\hline $\mathrm{Cl}<0.65$ & 420 & 0.017 & 0.020 & 0.023 & 0.026 & 0.026 & 1.477 & $0.766-2.847$ & 0.240 \\
\hline $\mathrm{Cl} \geq 0.65$ & 505 & 0.027 & 0.043 & 0.048 & 0.048 & 0.051 & & & \\
\hline $\mathrm{G} \mid<3.1$ & 470 & 0.019 & 0.022 & 0.024 & 0.027 & 0.030 & 1.486 & $0.781-2.827$ & 0.23 \\
\hline $\mathrm{GI} \geq 3.1$ & 455 & 0.026 & 0.044 & 0.049 & 0.049 & 0.049 & & & \\
\hline Single shot & 199 & 0.005 & 0.010 & 0.010 & 0.022 & 0.022 & & & \\
\hline $\mathrm{Cl}<0.65$ & 168 & 0.006 & 0.006 & 0.012 & 0.020 & 0.020 & 3.764 & $0.631-22.45$ & 0.14 \\
\hline $\mathrm{Cl} \geq 0.65$ & 31 & 0.000 & 0.036 & 0.036 & 0.036 & 0.036 & & & \\
\hline $\mathrm{Gl}<3.1$ & 252 & 0.025 & 0.030 & 0.030 & 0.030 & 0.030 & 1.079 & $0.525-2.271$ & 0.83 \\
\hline $\mathrm{GI} \geq 3.1$ & 474 & 0.029 & 0.043 & 0.049 & 0.049 & 0.052 & & & \\
\hline Multiple shots & 726 & 0.027 & 0.039 & 0.042 & 0.042 & 0.045 & & & \\
\hline $\mathrm{Cl}<0.65$ & 254 & 0.025 & 0.030 & 0.030 & 0.030 & 0.030 & 1.079 & $0.525-2.217$ & 0.83 \\
\hline $\mathrm{Cl} \geq 0.65$ & 474 & 0.029 & 0.043 & 0.049 & 0.049 & 0.052 & & & \\
\hline $\mathrm{G} \mid<3.1$ & 322 & 0.025 & 0.029 & 0.029 & 0.029 & 0.034 & 1.449 & $0.713-2.943$ & 0.31 \\
\hline $\mathrm{GI} \geq 3.1$ & 404 & 0.029 & 0.047 & 0.053 & 0.053 & 0.053 & & & \\
\hline $\mathrm{Vol}<5.0 \mathrm{~cm}^{3}$ & 484 & 0.013 & 0.022 & 0.027 & 0.030 & 0.030 & & & \\
\hline $\mathrm{Cl}<0.65$ & 309 & 0.010 & 0.013 & 0.017 & 0.021 & 0.021 & 1.675 & $0.649-4.235$ & 0.28 \\
\hline $\mathrm{Cl} \geq 0.65$ & 175 & 0.018 & 0.038 & 0.046 & 0.046 & 0.046 & & & \\
\hline $\mathrm{Gl}<3.1$ & 228 & 0.014 & 0.014 & 0.019 & 0.024 & 0.024 & 1.297 & $0.496-3.395$ & 0.59 \\
\hline $\mathrm{GI} \geq 3.1$ & 256 & 0.012 & 0.030 & 0.035 & 0.035 & 0.035 & & & \\
\hline $\mathrm{Vol} \geq 5.0 \mathrm{~cm}^{3}$ & 441 & 0.033 & 0.044 & 0.047 & 0.047 & 0.050 & & & \\
\hline $\mathrm{Cl}<0.65$ & 111 & 0.039 & 0.039 & 0.039 & 0.039 & 0.039 & 1.064 & $0.391-2.891$ & 0.90 \\
\hline $\mathrm{Cl} \geq 0.65$ & 330 & 0.032 & 0.045 & 0.049 & 0.049 & 0.053 & & & \\
\hline $\mathrm{Gl}<3.1$ & 242 & 0.025 & 0.030 & 0.030 & 0.030 & 0.035 & 1.733 & $0.731-4.112$ & 0.21 \\
\hline $\mathrm{GI} \geq 3.1$ & 199 & 0.044 & 0.062 & 0.069 & 0.069 & 0.069 & & & \\
\hline
\end{tabular}

to identify clinical factors associated with the incidences of complications and local progression. Also, to identify baseline and clinical variables associated with local progression and complications, competing risk analyses were performed with the Fine-Gray generalization of the proportional hazards model. ${ }^{1,2}$ The adjusted hazard ratio (HR), 95\% confidence intervals, and $\mathrm{p}$ values were initially calculated with multivariable analyses. A p value of less than 0.05 was regarded as indicating a statistically significant difference.

All statistical analyses were performed by a statistician (Y.S.) using SAS software version 9.4 (SAS Institute). Prior to the statistical analyses, the database was cleaned by one of the coauthors (Y.H.). These two authors were not involved in either SRS treatment or patient follow-up.

\section{Results}

As of December 2016, the median post-SRS observation time among censored observations (144 patients) was 10.0 (IQR 4.3-21.0, maximum 201.5) months and 781 patients $(84.4 \%)$ had died. The overall median survival time after SRS was 11.4 (95\% confidence interval 10.1-12.4, IQR 5.0-25.5) months. Actuarial post-SRS survival rates were $70.3 \%, 47.7 \%, 26.4 \%, 17.3 \%, 12.1 \%$, and $10.7 \%$ at the 6th, 12th, 24th, 36th, 48th, and 60th post-SRS month, re- spectively. Among the 781 patients who died, causes of death could not be determined in 27 , but were confirmed in the remaining 754 to be nonbrain disease in 666 (88.3\%) and brain disease in $88(11.7 \%)$.

During a median post-SRS observation period of 9.7 (IQR 4.2-20.5, maximum 201.5) months, SRS-related complications occurred in 38 patients $(4.1 \%)$, with a median post-SRS interval of 11.5 (IQR 6.0-25.8, maximum $118.0)$ months. Cumulative incidences of post-SRS complications determined by a competing risk analysis were $2.2 \%, 3.2 \%, 3.6 \%, 3.8 \%$, and $3.9 \%$ at the 12 th, 24 th, 36th, 48th, and 60th post-SRS month, respectively (Table 3). Among the 925 patients, post-SRS MRI was performed at least once in 716, who were thus eligible for local progression evaluation. Among these 716 patients, local progression was confirmed in 96 (13.4\%), with a median post-SRS interval of 10.8 (IQR 6.7-19.5, maximum 59.8) months. Cumulative incidences of local progression determined by a competing risk analysis were $7.7 \%, 12.6 \%, 14.2 \%$, $14.8 \%$, and $15.3 \%$ at the 12th, 24th, 36th, 48th, and 60th post-SRS month, respectively (Table 4).

As shown in Table 5, multivariable analyses revealed that only two clinical factors-i.e., peripheral doses and brain volume receiving $\geq 12 \mathrm{~Gy}$-correlated with complication rates. However, neither CIs nor GIs impacted the incidences of complications. Cumulative incidences of 
TABLE 4. Cumulative incidences of local progression after stereotactic radiosurgery

\begin{tabular}{|c|c|c|c|c|c|c|c|c|c|}
\hline \multirow{2}{*}{$\begin{array}{l}\text { Cumulative } \\
\text { Incidences }\end{array}$} & \multirow[b]{2}{*}{ No. } & \multicolumn{5}{|c|}{ Mos After SRS } & \multirow{2}{*}{$\begin{array}{c}\text { Adjusted } \\
\text { HR }\end{array}$} & \multirow{2}{*}{$\begin{array}{c}95 \% \text { Confidence } \\
\text { Interval }\end{array}$} & \multirow{2}{*}{$\begin{array}{c}p \\
\text { Value }\end{array}$} \\
\hline & & 12 & 24 & 36 & 48 & 60 & & & \\
\hline Overall & 718 & 0.077 & 0.126 & 0.142 & 0.148 & 0.153 & & & \\
\hline $\mathrm{Cl}<0.65$ & 344 & 0.052 & 0.094 & 0.101 & 0.110 & 0.110 & 1.870 & $1.299-2.843$ & 0.0034 \\
\hline $\mathrm{Cl} \geq 0.65$ & 374 & 0.100 & 0.156 & 0.181 & 0.185 & 0.194 & & & \\
\hline $\mathrm{G} \mid<3.1$ & 355 & 0.102 & 0.148 & 0.163 & 0.167 & 0.176 & 0.693 & $0.463-1.037$ & 0.074 \\
\hline $\mathrm{GI} \geq 3.1$ & 363 & 0.051 & 0.104 & 0.122 & 0.130 & 0.130 & & & \\
\hline Single shot & 156 & 0.060 & 0.081 & 0.096 & 0.104 & 0.113 & & & \\
\hline $\mathrm{Cl}<0.65$ & 136 & 0.053 & 0.078 & 0.078 & 0.088 & 0.088 & 3.374 & $1.206-9.434$ & 0.020 \\
\hline $\mathrm{Cl} \geq 0.65$ & 20 & 0.105 & 0.105 & 0.222 & 0.222 & 0.295 & & & \\
\hline $\mathrm{Gl}<3.1$ & 112 & 0.064 & 0.093 & 0.114 & 0.114 & 0.126 & 0.592 & $0.170-2.062$ & 0.41 \\
\hline $\mathrm{GI} \geq 3.1$ & 44 & 0.049 & 0.049 & 0.049 & 0.080 & 0.080 & & & \\
\hline Multiple shots & 562 & 0.082 & 0.140 & 0.157 & 0.162 & 0.165 & & & \\
\hline $\mathrm{Cl}<0.65$ & 208 & 0.051 & 0.105 & 0.119 & 0.127 & 0.127 & 1.608 & $0.968-2.618$ & 0.056 \\
\hline $\mathrm{Cl} \geq 0.65$ & 354 & 0.100 & 0.159 & 0.178 & 0.182 & 0.187 & & & \\
\hline $\mathrm{GI}<3.1$ & 243 & 0.120 & 0.175 & 0.187 & 0.193 & 0.201 & 0.635 & $0.410-0.982$ & 0.041 \\
\hline $\mathrm{GI} \geq 3.1$ & 319 & 0.051 & 0.112 & 0.133 & 0.138 & 0.138 & & & \\
\hline Vol $<5.0 \mathrm{~cm}^{3}$ & 392 & 0.051 & 0.087 & 0.100 & 0.104 & 0.111 & & & \\
\hline $\mathrm{Cl}<0.65$ & 259 & 0.036 & 0.064 & 0.064 & 0.069 & 0.069 & 2.913 & $1.532-5.539$ & 0.0010 \\
\hline $\mathrm{Cl} \geq 0.65$ & 133 & 0.080 & 0.132 & 0.176 & 0.176 & 0.201 & & & \\
\hline $\mathrm{G} \mid<3.1$ & 179 & 0.058 & 0.091 & 0.106 & 0.106 & 0.125 & 0.839 & $0.445-1.581$ & 0.58 \\
\hline $\mathrm{GI} \geq 3.1$ & 213 & 0.045 & 0.083 & 0.095 & 0.102 & 0.102 & & & \\
\hline Vol $\geq 5.0 \mathrm{~cm}^{3}$ & 326 & 0.109 & 0.174 & 0.194 & 0.203 & 0.203 & & & \\
\hline $\mathrm{Cl}<0.65$ & 85 & 0.101 & 0.189 & 0.223 & 0.242 & 0.242 & 0.835 & $0.478-1.456$ & 0.52 \\
\hline $\mathrm{Cl} \geq 0.65$ & 241 & 0.111 & 0.168 & 0.183 & 0.189 & 0.189 & & & \\
\hline $\mathrm{GI}<3.1$ & 176 & 0.147 & 0.205 & 0.219 & 0.227 & 0.227 & 0.664 & $0.392-1.124$ & 0.12 \\
\hline $\mathrm{GI} \geq 3.1$ & 150 & 0.061 & 0.135 & 0.163 & 0.173 & 0.173 & & & \\
\hline
\end{tabular}

Based on 718 patients; i.e., 207 patients were excluded because neuroimaging results were not available.

complications were assessed by dividing the patients into groups (i.e., single vs multiple shots and those with a tumor volume $<5 \mathrm{~cm}^{3} \mathrm{vs} \geq 5 \mathrm{~cm}^{3}$, along with CIs $<0.65$ vs $\geq$ 0.65 or GIs $<3.1$ vs $\geq 3.1$, as demonstrated in Table 3. No statistically significant differences were detected in any of these subgroup analyses.

Also, as shown in Table 6, multivariable analyses revealed that neurological symptoms, extracerebral metastases, and CIs correlated with incidences of local progression, whereas GIs were not associated with local tumor progression. As shown in Table 4, cumulative incidences of local progression were significantly lower in patients with CIs < 0.65 than in those with CIs $\geq 0.65$ (adjusted HR 1.870, 95\% confidence interval $1.299-2.843 ; \mathrm{p}=0.0034)$. These results were also obtained in subgroups of patients receiving single-shot treatment (adjusted HR 3.374, 95\% confidence interval 1.206-9.434; $\mathrm{p}=0.020$ ) as well as in those with tumor volumes $<5 \mathrm{~cm}^{3}$ (adjusted HR 2.913, 95\% confidence interval $1.532-5.539 ; p=0.0010$ ). In a subgroup of patients receiving multiple-shot treatment, cumulative incidences of local progression were significantly lower in those with GIs $\geq 3.1$ than in patients with GIs $<3.1$ (adjusted HR 0.635, $95 \%$ confidence interval $0.410-0.982 ; \mathrm{p}=0.041$ ).

Regarding neurologically qualitative survival, ${ }^{24}$ there was no significant difference in maintained Karnofsky
Performance Scale (KPS) score $(<20 \%$ decrease due to neurological diseases) between the two groups with GI $\geq 3.1$ and GI $<3.1$ (HR $0.810,95 \%$ confidence interval $0.562-1.161 ; p=0.2059)$. Nevertheless, the cumulative rate of maintained KPS score was significantly higher in patients with $\mathrm{CI}<0.65$ than in those with $\mathrm{CI} \geq 6.5$ (HR $0.511,95 \%$ confidence interval $0.350-0.738 ; p=0.0003$ ).

\section{Discussion}

In comments on our previous publication focusing on delayed cyst formation in patients with BM surviving > 3 years after SRS, Regis stated that the mean GI value in our series was quite poor (approximately 4) and noted that cyst formation might partially account for this result., ${ }^{4} 13$ However, we have long wondered whether either CI or GI truly impacts treatment results, despite these indexes being theoretically regarded as correlating with post-SRS outcomes. We reported that, based on 207 patients with vestibular schwannomas who were followed up for at least 10 years after SRS, CI did not correlate with good tumor control and GI had no impact on the degree of hearing preservation. ${ }^{15}$ Nevertheless, to our knowledge the present study is the first analysis to focus on the clinical significance of CI and GI based on a large patient series. 
TABLE 5. Multivariable analyses of complications after SRS

\begin{tabular}{|c|c|c|c|c|}
\hline Variable & Comparison & $\mathrm{HR}$ & 95\% Confidence Interval & $p$ Value \\
\hline Sex & Male vs female & 0.896 & $0.372-2.161$ & 0.81 \\
\hline Age (yrs) & $\geq 65$ vs $<65$ & 1.102 & $0.536-2.267$ & 0.79 \\
\hline KPS score (\%) & $\leq 70$ vs $\geq 80$ & 2.601 & $0.789-8.575$ & 0.12 \\
\hline \multirow[t]{2}{*}{ Modified RPA class* } & $2 c+3$ vs $1+2 a$ & 1.193 & $0.255-5.577$ & 0.82 \\
\hline & $2 c+3$ vs $2 b$ & 1.099 & $0.287-4.217$ & 0.89 \\
\hline Symptomatic & Yes vs no & 0.543 & $0.265-1.112$ & 0.095 \\
\hline Pre-SRS surgery & Yes vs no & 2.872 & $0.981-8.404$ & 0.054 \\
\hline Pre-SRS WBRT & Yes vs no & 0.226 & $0.041-1.242$ & 0.087 \\
\hline Tumor vol $\left(\mathrm{cm}^{3}\right)$ & $\geq 5.0$ vs $<5.0$ & 1.158 & $0.397-3.381$ & 0.79 \\
\hline Nos. of target points & Multiple vs single & 1.535 & $0.362-6.505$ & 0.56 \\
\hline Peripheral dose (Gy) & $\geq 20$ vs $<20$ & 0.235 & $0.059-0.932$ & 0.039 \\
\hline Max dose (Gy) & $\geq 35$ vs $<35$ & 1.279 & $0.401-4.077$ & 0.68 \\
\hline Brain vol receiving $\geq 12 \mathrm{~Gy}\left(\mathrm{~cm}^{3}\right)$ & $\geq 30$ vs $<30$ & 0.349 & $0.125-0.973$ & 0.044 \\
\hline Original tumor status & Non- vs well-controlled & 2.141 & $0.907-5.056$ & 0.083 \\
\hline \multicolumn{5}{|l|}{ Original tumor } \\
\hline & SCLC vs breast & 2.195 & $0.42-11.463$ & 0.35 \\
\hline & SCLC vs GI & 0.143 & $0.011-1.781$ & 0.13 \\
\hline & SCLC vs kidney & 1.702 & $0.302-9.591$ & 0.55 \\
\hline & SCLC vs NSCLC & 0.887 & $0.246-3.206$ & 0.86 \\
\hline & SCLC vs others & 0.488 & $0.072-3.292$ & 0.46 \\
\hline Extracerebral metastases & Yes vs no & 1.518 & $0.499-4.617$ & 0.46 \\
\hline $\mathrm{GI}$ & $\geq 3.1$ vs 3.1 & 1.275 & $0.635-2.562$ & 0.49 \\
\hline $\mathrm{Cl}$ & $\geq 0.65$ vs $<0.65$ & 0.738 & $0.311-1.752$ & 0.49 \\
\hline
\end{tabular}

It is widely believed that an optimal dose plan for SRS would be based on a higher CI (nearer 1.0) and a lower GI. However, the present study clarified that this assumption is not applicable to SRS for BM. Rather, we found that the lower a CI was, the lower the local progression rate was. This observation was even more remarkable in subgroups of patients with relatively small tumors $\left(<5.0 \mathrm{~cm}^{3}\right)$ or in those who had received single-shot treatment. Although in GK SRS the tumor volume is the same as the planned target volume, a margin of a few millimeters may be reasonable, as is generally applied in LINAC-based SRS, particularly in GK SRS for rather small tumors (i.e., 2-3 mm in diameter), with a single isocenter. In such a case, even if a $90 \%$ or $95 \%$ isodose gradient is used, with a coverage rate of 1.0 , the selectivity rate is very low. Therefore, the $\mathrm{CI}$ is calculated to be $0.2-0.1$, or even lower. However, the absolute volume of the normal brain tissue included within the target volume is usually very small. In contrast, in the present study, GI was clearly shown to have a minimal impact in lowering the incidence of complications. Although a higher GI was shown to correlate with a lower incidence of local progression, this was only in the subset of patients receiving multiple-shot treatment. These observations appear to support the aforementioned results obtained using a margin of a few millimeters.

Nakamura et al. reported that the median CIs (the ratio of the prescription volume to the target volume) were 1.67 for all 1338 evaluable lesions and 1.40-1.43 for lesions similar to those in two LINAC radiosurgery series that reported CIs of 1.8 and 2.7, respectively. ${ }^{8}$ However, they did not describe further analyses. Sneed et al. reported that, based on their analysis of 2049 lesions, the median CI was 0.5 (IQR $0.35-0.66) .{ }^{14}$ These data were slightly worse than ours-i.e., median 0.66 and IQR $0.53-0.74$. Although they also noted, based on analysis of 1831 lesions, that the median GI was 3.18 (IQR 2.85-3.74), the method applied to GI determination in patients with multiple BMs was not described. Their cohort consisted of 435 patients, considerable numbers of whom had multiple BMs (Paddick's GI can be correctly calculated only in patients with a single BM). Nevertheless, Sneed et al.'s GI data were very similar to ours-i.e., median 3.09 and IQR 2.83-3.39. They concluded that there were no significant influences of either the Paddick CI or the GI on the risk of adverse radiation effect with target volumes $>1.0 \mathrm{~cm}^{3}$. In our study, CI did not significantly impact local progression rates (as a continuous variable, HR was $0.737,95 \%$ confidence interval 0.034-18.46; $\mathrm{p}=0.8485$ ) in patients with tumor volumes $>1.0 \mathrm{~cm}^{3}$. However, CI did significantly influence local progression rates (as a continuous variable, HR was 5.626, 95\% confidence interval $1.064-34.86 ; \mathrm{p}=0.0417)$ in patients with tumor volumes $<5.0 \mathrm{~cm}^{3}$.

The major weakness of this study is the retrospective design. There were considerable biases in patient selection and post-SRS observations. The second weakness is that post-SRS neuroimaging data were lacking in $22 \%$ of 
TABLE 6. Multivariable analyses of local progression after SRS

\begin{tabular}{|c|c|c|c|c|}
\hline Variable & Comparison & $\mathrm{HR}$ & 95\% Confidence Interval & p Value \\
\hline Age (yrs) & $\geq 65$ vs $<65$ & 0.950 & $0.608-1.485$ & 0.82 \\
\hline Sex & Male vs female & 0.791 & $0.501-1.248$ & 0.31 \\
\hline KPS score (\%) & $\leq 70$ vs $\geq 80$ & 1.792 & $0.886-3.625$ & 0.10 \\
\hline \multirow[t]{2}{*}{ Modified RPA class* } & $2 c+3$ vs $1+2 a$ & 0.829 & $0.283-2.431$ & 0.73 \\
\hline & $2 c+3$ vs $2 b$ & 1.493 & $0.608-3.670$ & 0.38 \\
\hline Symptomatic & Yes vs no & 0.577 & $0.342-0.973$ & 0.039 \\
\hline Pre-SRS surgery & Yes vs no & 0.789 & $0.456-1.366$ & 0.40 \\
\hline Pre-SRS WBRT & Yes vs no & 1.855 & $0.332-10.368$ & 0.48 \\
\hline Tumor vol $\left(\mathrm{cm}^{3}\right)$ & $\geq 5.0$ vs $<5.0$ & 0.961 & $0.508-1.818$ & 0.90 \\
\hline Nos. of target points & Multiple vs single & 0.588 & $0.272-1.274$ & 0.18 \\
\hline Peripheral dose (Gy) & $\geq 20$ vs $<20$ & 1.086 & $0.579-2.035$ & 0.80 \\
\hline Max dose (Gy) & $\geq 35$ vs $<35$ & 1.023 & $0.608-1.721$ & 0.93 \\
\hline Brain vol receiving $\geq 12 \mathrm{~Gy}\left(\mathrm{~cm}^{3}\right)$ & $\geq 30$ vs $<30$ & 0.619 & $0.334-1.145$ & 0.13 \\
\hline Original tumor status & Non- vs well-controlled & 1.518 & $0.869-2.651$ & 0.14 \\
\hline \multicolumn{5}{|l|}{ Original tumor } \\
\hline & SCLC vs breast & 0.978 & $0.330-2.895$ & 0.97 \\
\hline & SCLC vs GI & 1.252 & $0.503-3.115$ & 0.63 \\
\hline & SCLC vs kidney & 0.551 & $0.141-2.151$ & 0.39 \\
\hline & SCLC vs NSCLC & 0.584 & $0.254-1.342$ & 0.21 \\
\hline & SCLC vs others & 0.305 & $0.072-1.296$ & 0.11 \\
\hline Extracerebral metastases & Yes vs no & 2.640 & $1.424-4.895$ & 0.0021 \\
\hline $\mathrm{GI}$ & $\geq 3.1$ vs 3.1 & 0.719 & $0.447-1.156$ & 0.17 \\
\hline $\mathrm{Cl}$ & $\geq 0.65$ vs $<0.65$ & 0.474 & $0.276-0.814$ & 0.0068 \\
\hline
\end{tabular}

Based on 718 patients; i.e., 207 patients were excluded because neuroimaging results were not available.

${ }^{*}$ Categorized according to Yamamoto and colleagues. ${ }^{21,23}$

our patients, mainly because of rapid worsening of their general condition, eventually resulting in death with a relatively short survival period after SRS (median survival time was 2.7 months in this group). The third weakness is that all patients with mild and/or transient complications probably were not included because most of the patients in our cohort were managed by physicians in other hospitals, such that less serious complications probably were not reported to us. Therefore, our complication incidence was lower than those reported by Sneed et al. and by Williams et al..$^{14,17}$ In their reported series, convulsive seizures were counted. However, convulsive seizure is regarded as one of the major symptoms caused by a BM itself. Thus, we did not count convulsive seizures as SRS-related complications. However, we are highly confident that relatively severe complications were reported to us. Thus, we assessed patients with RTOG Neurotoxicity grade 2 or worse in this study. As mentioned above, this criterion has reportedly remained consistent for many years and is widely accepted, as documented in our previous publications. ${ }^{6,16,18-20,22,24}$ The fourth weakness of our study is that data on systemic anticancer agent treatments were insufficient because, as mentioned above, systemic cancers were managed by referring physicians who worked at different facilities. Therefore, we could not survey whether systemic anticancer agent therapy had been administered or any potential effects of such treatments, which probably means that the results reported herein do not adhere to the modern strategies for management of patients with BM, particularly those with non-small cell lung cancer (NSCLC).

Our results are strictly applicable only to patients with a single BM irradiated by SRS. As the next step in the process of evaluating the utility of the GI, we hope to develop a novel method by which the GI can be correctly calculated even in patients with multiple intracranial lesions. As is well known, the present method for GI calculation is applicable only to patients with a single target in the cranium. At present, we have no method of calculating the GI in patients with multiple intracranial lesions.

\section{Conclusions}

We believe this to be the first analysis focusing on the clinical significance of CI and GI based on a large series of patients with BM. Contrary to the majority opinion that dose planning with a higher CI and a lower GI produces good post-SRS outcomes (i.e., low local progression and minimal complications), this study clearly demonstrated that lower CIs are associated with lower local progression rates and that GI has no impact on complication rates.

\section{Acknowledgments}

We are very grateful to Bierta E. Barfod, MD, Katsuta Hospital Mito GammaHouse, for her help with the language editing of this manuscript. 


\section{References}

1. Fine JP, Gray RJ: A proportional hazards model for the subdistribution of a competing risk. J Am Stat Assoc 94:496509,1999

2. Gooley TA, Leisenring W, Crowley J, Storer BE: Estimation of failure probabilities in the presence of competing risks: new representations of old estimators. Stat Med 18:695-706, 1999

3. Higuchi Y, Serizawa T, Nagano O, Matsuda S, Ono J, Sato M, et al: Three-staged stereotactic radiotherapy without whole brain irradiation for large metastatic brain tumors. Int J Radiat Oncol Biol Phys 74:1543-1548, 2009

4. Ishikawa E, Yamamoto M, Saito A, Kujiraoka Y, Iijima T, Akutsu H, et al: Delayed cyst formation after gamma knife radiosurgery for brain metastases. Neurosurgery 65:689695,2009

5. Kano H, Kondziolka D, Lobato-Polo J, Zorro O, Flickinger JC, Lunsford LD: T1/T2 matching to differentiate tumor growth from radiation effects after stereotactic radiosurgery. Neurosurgery 66:486-492, 2010

6. Koiso T, Yamamoto M, Kawabe T, Watanabe S, Sato Y, Higuchi Y, et al: Follow-up results of brain metastasis patients undergoing repeat Gamma Knife radiosurgery. J Neurosurg 125 (Suppl 1):2-10, 2016

7. Momose T, Nariai T, Kawabe T, Inaji M, Tanaka Y, Watanabe $\mathrm{S}$, et al: Clinical benefit of $11 \mathrm{C}$ methionine PET imaging as a planning modality for radiosurgery of previously irradiated recurrent brain metastases. Clin Nucl Med 39:939-943, 2014

8. Nakamura JL, Verhey LJ, Smith V, Petti PL, Lamborn KR, Larson DA, et al: Dose conformity of gamma knife radiosurgery and risk factors for complications. Int J Radiat Oncol Biol Phys 51:1313-1319, 2001

9. Nariai T, Tanaka Y, Wakimoto H, Aoyagi M, Tamaki M, Ishiwata K, et al: Usefulness of $\mathrm{L}-\left[\right.$ methyl $\left.{ }^{-1}{ }^{11} \mathrm{C}\right]$ methioninepositron emission tomography as a biological monitoring tool in the treatment of glioma. J Neurosurg 103:498-507, 2005

10. Paddick I: A simple scoring ratio to index the conformity of radiosurgical treatment plans. Technical note. J Neurosurg 93 (Suppl 3):219-222, 2000

11. Paddick I, Lippitz B: A simple dose gradient measurement tool to complement the conformity index. J Neurosurg 105 Suppl:194-201, 2006

12. Radiation Therapy Oncology Group: Cooperative group common toxicity criteria. RTOG.org (https://www.rtog.org/ ResearchAssociates/AdverseEventReporting/CooperativeGroupCommonToxicityCriteria.aspx) [Accessed July 16, 2018]

13. Regis J: Comment on "Delayed cyst formation after gamma knife radiosurgery for brain metastases." Neurosurgery 65:695, 2009

14. Sneed PK, Mendez J, Vemer-van den Hoek JGM, Seymour ZA, Ma L, Molinaro AM, et al: Adverse radiation effect after stereotactic radiosurgery for brain metastases: incidence, time course, and risk factors. J Neurosurg 123:373-386, 2015

15. Watanabe S, Yamamoto M, Kawabe T, Koiso T, Yamamoto T, Matsumura A, et al: Stereotactic radiosurgery for vestibular schwannomas: average 10-year follow-up results focusing on long-term hearing preservation. J Neurosurg 125 (Suppl 1):64-72, 2016

16. Watanabe S, Yamamoto M, Sato Y, Kawabe T, Higuchi Y, Kasuya $\mathrm{H}$, et al: Stereotactic radiosurgery for brain metastases: a case-matched study comparing treatment results for patients 80 years of age or older versus patients $65-79$ years of age. J Neurosurg 121:1148-1157, 2014

17. Williams BJ, Suki D, Fox BD, Pelloski CE, Maldaun MVC, Sawaya RE, et al: Stereotactic radiosurgery for metastatic brain tumors: a comprehensive review of complications. J Neurosurg 111:439-448, 2009
18. Yamamoto M, Kawabe T, Higuchi Y, Sato Y, Nariai T, Barfod BE, et al: Delayed complications in patients surviving at least 3 years after stereotactic radiosurgery for brain metastases. Int J Radiat Oncol Biol Phys 85:53-60, 2013

19. Yamamoto M, Kawabe T, Sato Y, Higuchi Y, Nariai T, Barfod BE, et al: A case-matched study of stereotactic radiosurgery for patients with multiple brain metastases: comparing treatment results for $1-4$ vs $\geq 5$ tumors: clinical article. J Neurosurg 118:1258-1268, 2013

20. Yamamoto M, Kawabe T, Sato Y, Higuchi Y, Nariai T, Watanabe $S$, et al: Stereotactic radiosurgery for patients with multiple brain metastases: a case-matched study comparing treatment results for patients with 2-9 versus 10 or more tumors. J Neurosurg 121 Suppl:16-25, 2014

21. Yamamoto M, Sato Y, Serizawa T, Kawabe T, Higuchi Y, Nagano O, et al: Subclassification of recursive partitioning analysis Class II patients with brain metastases treated radiosurgically. Int J Radiat Oncol Biol Phys 83:1399-1405, 2012

22. Yamamoto M, Serizawa T, Higuchi Y, Sato Y, Kawagishi J, Yamanaka K, et al: A multi-institutional prospective observational study of stereotactic radiosurgery for patients with multiple brain metastases (JLGK0901 study update): irradiation-related complications and long-term maintenance of Mini-Mental State Examination Scores. Int J Radiat Oncol Biol Phys 99:31-40, 2017

23. Yamamoto M, Serizawa T, Sato Y, Kawabe T, Higuchi Y, Nagano O, et al: Validity of two recently-proposed prognostic grading indices for lung, gastro-intestinal, breast and renal cell cancer patients with radiosurgically-treated brain metastases. J Neurooncol 111:327-335, 2013

24. Yamamoto M, Serizawa T, Shuto T, Akabane A, Higuchi Y, Kawagishi J, et al: Stereotactic radiosurgery for patients with multiple brain metastases (JLGK0901): a multi-institutional prospective observational study. Lancet Oncol 15:387-395, 2014

\section{Disclosures}

The authors report no conflict of interest concerning the materials or methods used in this study or the findings specified in this paper.

\section{Author Contributions}

Conception and design: M Yamamoto, Ishikawa. Acquisition of data: Aiyama, Kawabe, Watanabe, Koiso. Analysis and interpretation of data: Aiyama. Drafting the article: Aiyama. Critically revising the article: M Yamamoto, Aiyama, Kawabe, Watanabe, Koiso, Ishikawa, Matsumura, Kasuya. Reviewed submitted version of manuscript: all authors. Approved the final version of the manuscript on behalf of all authors: M Yamamoto. Statistical analysis: Sato, Higuchi. Administrative/technical/material support: Matsumura, Kasuya. Study supervision: M Yamamoto, Ishikawa, T Yamamoto, Matsumura, Kasuya.

\section{Supplemental Information}

Previous Presentations

This work was presented in oral form at the 19th Meeting of the Leksell Gamma Knife Society, Dubai, United Arab Emirates, March 4-8, 2018.

\section{Correspondence}

Masaaki Yamamoto: Katsuta Hospital Mito GammaHouse, Ibaraki, Japan.bcd06275@nifty.com. 